\title{
Effects of second-hand smoking on lung functions in athlete and non-athlete school-aged children - observational study
}

\author{
Fathi A Elshazly ${ }^{1}$, Walid K Abdelbasset ${ }^{1,2}$, Ragab K Elnaggar ${ }^{1,3}$, Sayed A Tantawy ${ }^{4,5}$
}

1. Department of Physical Therapy and Health Rehabilitation, College of Applied Medical Sciences, Prince Sattam Bin Abdulaziz University, Alkharj, Saudi Arabia.

2. Department of Physical Therapy, Kasr Al-Aini Hospital, Cairo University, Giza, Egypt.

3. Department of Physical Therapy for Pediatrics, Faculty of Physical Therapy, Cairo University, Giza, Egypt.

4. Department of Physiotherapy, College of Medical and Health Sciences, Ahlia University, Manama, Bahrain.

5. Department of Physiotherapy, Centre of Radiation, Oncology and Nuclear Medicine, Cairo University, Giza, Egypt.

\begin{abstract}
Background: Second-hand smoking or environmental tobacco smoke is a critical health risk. Children are the most vulnerable to second-hand smoking because of their small bronchial ducts, less developed immunity, and low-physical activity.

Objectives: The purpose of this study was to ascertain the effects of second-hand smoking on lung functions in athlete and non-athlete school-aged children.

Methods: This observational study included forty-six school-aged children, their age was 8-15 years, assigned to three groups; 2 study groups and 1 control group $(\mathrm{n}=15)$. The study groups comprised of 16 football players, and of 15 cyclists. Lung functions were evaluated recording forced vital capacity, forced expiratory volume in $1 \mathrm{sec}$ and peak expiratory flow using digital spirometer.

Results: All measures were recorded in definite values and the children were also classified into second-hand smoking ( $\mathrm{SH}$ ), or non-exposed to tobacco smoking $(\mathrm{NE})$. The findings presented a significant increase $(\mathrm{p}<0.05)$ of the study groups in forced vital capacity, forced expiratory volume in $1 \mathrm{sec}$ and peak expiratory flow solely for the non-exposed children. However, there were non-significant differences between the cyclists and football players or between the passive smoking children and non-exposed children in any of the two study groups ( $\mathrm{p}>0.05)$.

Conclusion: The outcomes of this study suggest beneficial influences of the sports activity on the lung functions, without different influences of the cyclists and football players on the lung functions.

Keywords: Children, second-hand smoking, lung functions, athlete.

DOI: https://dx.doi.org/10.4314/ahs.v20i1.42

Cite as: Elshazly FA, Abdelbasset WK, Elnaggar RK, Tantany SA. Effects of second-hand smoking on lung functions in athlete and non-athlete school-aged children - observational study. Afri Health Sci. 2020;20(1):368-75. https:// dx.doi.org/10.4314/abs.v20i1.42
\end{abstract}

\section{Introduction}

The most common worldwide health problem is environmental tobacco smoking affecting mostly children and

\section{Corresponding author:}

Walid Kamal Abdelbasset,

Department of Physical Therapy and Health

Rehabilitation, College of Applied Medical

Sciences, Prince Sattam Bin Abdulaziz

University, Alkharj, Saudi Arabia.

Mobile: +966561014872

Email: walidkamal.wr@gmail.com enforces their health risks, regrettably induced primarily by parents and relatives. Environmental tobacco smoking includes many chemical contents; the most of these contents are poisonous, aggravating, or active substances, and number of these result in cancer. ${ }^{1}$

The World Health Organization (WHO) reported that seven-hundred million children worldwide (nearly, forty percent of all children) are revealed to passive smoking at home. Second-hand smoking $(\mathrm{SH})$ is approximated causing about 600,000 deaths of pre-pubescent yearly worldwide. SH causes thirty-one percentages of all deaths occurring among children. ${ }^{2}$ Also, previous study concluded cited. 
that passive smoking may affect the protective characteristics of saliva and decrease oral health condition in children. ${ }^{3}$ The researchers reported a strong relationship between $\mathrm{SH}$ and pulmonary disorders in the young children. A reduction in lung volumes was documented in young children who exposed to environmental tobacco smoking $^{4}$, especially in asthmatics ${ }^{5}$ and those who exposed during the period of pregnancy. ${ }^{6}$

Recently, it was reported that pulmonary functions of growing children including, lung capacities, volumes, and flows alter mainly a biological functionality of age and therefore a functionality of body height. This process was identified as an increasing of the lung functions, which consequentially results from an increasing of body dimensions, usually demonstrated as an increasing of the body height. Nevertheless, lung functions are also associated with changes in the function of the pulmonary system, unnecessarily associated with growth. ${ }^{7}$ Second-hand smoking is formerly known as a passive smoking affecting pulmonary system negatively and causes a reduction in lung volumes ${ }^{8,9}$, particularly to those who exposed during the period of pregnancy $^{10}$, and those who have exposed to environmental tobacco smoking under five years. ${ }^{11}$

Additionally, it was hypothesized, even widely not studied, that exercise training and physical activity beneficially affect lung functions in children. ${ }^{12-14}$ Previous researches presented a significant increase in respiratory volumes of exercised young children in over an extended time ${ }^{12,13}$, and another research reported significant changes in pulmonary functions between athlete and non-athlete youngsters. ${ }^{14}$ On the contrary, there was clear unsuitability about the feasible factors which result in the increasing of athlete children in the respiratory volumes, when compared with the non-athletes. Briefly, there is no exact data confirms that exercise training and sports enhance respiratory volumes.

Even so, these researches were limited in sport-selecting impacts and, hence, the restricted statistical impact. Eventually, publications evaluating the effect of second-hand smoking and physical exercise on the lung functions in school-aged children are deficient. So that, this study evaluated the status of lung functions in sportive (football players and cyclists) and non-sportive school-aged children, and assessed the potential effect of $\mathrm{SH}$ on the lung functions. The current study hypothesized that the athlete children had better lung functions than age-related non-athlete peers and theynamics differences of the two sports activities may lead to evident changes in maximum oxygen consumption $\left(\mathrm{VO}_{2} \max \right)$ and suggested the clear different influences in the lung volumes in the two sportive groups. The purpose of this study was to ascertain the effects of second-hand smoking on lung functions in athlete and non-athlete school-aged children.

\section{Materials and methods \\ Subjects}

Between June and September 2018, this observational study (case-control study) included forty-six Egyptian school-aged children, their age was $8-15$ years with age mean of $10.8 \pm 2.7$ years. The forty-six children were classified into three groups (2 study groups and 1 control group). The two study groups were a group of football players' children $(n=16)$, and a group of cyclist children $(n=15)$. The control group $(n=15)$ did not receive any physical exercise a part of lung functions. All children did not suffer from a late health complications or any lung disorders. Parents or caregivers of the children were notified about the aim, procedure, and the benefits of the study, and signed a written informed consent. This study was approved by the ethical committee of the department of physical therapy based on the ethical standards of human research. The procedure of this study has performed according to the guidelines of the Declaration of Helsinki.

\section{Procedure}

Pulmonary function tests were applied using a digital spirometer (CONTEC: SP10, China). The same examiner who evaluated the children, was blinded concerning the group to which each child was assigned. Each child was instructed to deeply inspire as much as possible and then expire forcefully and rapidly for as long as flow can be preserved. The assessment was applied to the children in sitting position, the breath was done by way of a disposable mouthpiece with clipped nose.

Spirometer calibration was performed through a simple tube using the automatic program of calibration. The variables of lung functions included forced vital capacity (FVC), forced expiratory volume in 1 second (FEV1), and peak expiratory flow (PEF). In addition to lung functions, body weight and height were measured to calculate body mass index (BMI).

No child showed active smoking. The second-hand 
smoking ( $\mathrm{SH}$ ) was recognized by a questionnaire having the following 2 questions; first one, is anybody a smoker in your home? (if the answer was negative) the second question; has anybody ceased smoking in your home? If the answer of the first question was (yes) regarding, the child to be a second-hand smoking. When the answers of the 2 questions were (no) regarding the child to be non-exposed to tobacco smoking (NE). Eventually, the child was excluded from the study when only the answer of the second question was (yes). Also, the second-hand smoking was confirmed by caregiver or one parent. When the answer of the caregiver or the parents were counteract the results of the child questionnaire, the child was also excluded from the study. According to the inclusion criteria, three children only were excluded from the study groups. Spearman correlation coefficient showed a high reliability of the current questionnaire.

\section{Statistical analysis}

The descriptive statistics was used to calculate all parameters of the lung functions. The independent t-test was performed to assess the differences between the groups in age, weight, height, and BMI). Moreover, the multivariate analysis of the variance (MANOVA) was used to assess the lung function differences distinctly among the three groups. MANOVA assessed the lung function changes within football players, cyclists, and control groups concerning the smoking condition, and between football players, cyclists, and control groups (distinctly for $\mathrm{SH}$ and NE). The factor structure and the relationships' character among parameters were assessed using factor analysis. All data analysis were measured using SPSS, version 22 (SPSS, Chicago, IL, USA) with significance level of $\mathrm{P}<0.05$ for all measures.

\section{Results}

As demonstrated in table 1, the three groups did not show a significantly differ in gender, age, weight, height, and body mass index ( $p>0.05)$.

Comparative measures of lung function values are demonstrated and compared statistical differences between the groups, distinctly for the $\mathrm{SH}$ and $\mathrm{NE}$ subgroups. In the $\mathrm{NE}$; football and cycling groups showed significantly increasing of the lung function parameters when comparing with the measures of the control group $(\mathrm{p}<0.05)$. However, in the SH group, there were non-significant differences in the lung function parameters $(p>0.05)$ as showed in Figure 1.

Table 1: Baseline characteristics of the three groups of the study

\begin{tabular}{lcccc}
\hline Variables & $\begin{array}{c}\text { FB group } \\
\mathbf{n}=\mathbf{1 5}\end{array}$ & $\begin{array}{c}\text { CY group } \\
\mathbf{n = 1 6}\end{array}$ & $\begin{array}{c}\text { CO group } \\
\mathbf{n = 1 5}\end{array}$ & P-Value \\
\hline Gender $(\mathrm{M} / \mathrm{F})$ & $11 / 4$ & $11 / 5$ & $10 / 5$ & 0.999 \\
SH/NE & $9 / 6$ & $11 / 5$ & $10 / 5$ & 0.921 \\
Age $($ years $)$ & $10.9 \pm 2.8$ & $10.7 \pm 3.0$ & $10.8 \pm 2.6$ & 0.988 \\
Height $(\mathrm{cm})$ & $149.52 \pm 6.45$ & $150.64 \pm 7.61$ & $149.31 \pm 7.12$ & 0.856 \\
Weight $(\mathrm{kg})$ & $43.54 \pm 4.18$ & $44.65 \pm 5.25$ & $48.34 \pm 6.31$ & 0.548 \\
BMI $\left(\mathrm{kg} / \mathrm{m}^{2}\right)$ & $19.18 \pm 2.33$ & $19.84 \pm 3.12$ & $21.77 \pm 3.74$ & 0.758 \\
\hline
\end{tabular}

Abbreviations: Significant at $\mathrm{p}<0.05$; FB, football; CY, cycling; CO, control; M, males; F, females; SH, second-hand smokers; NE, non-exposed to tobacco smoke; BMI, body mass index. 


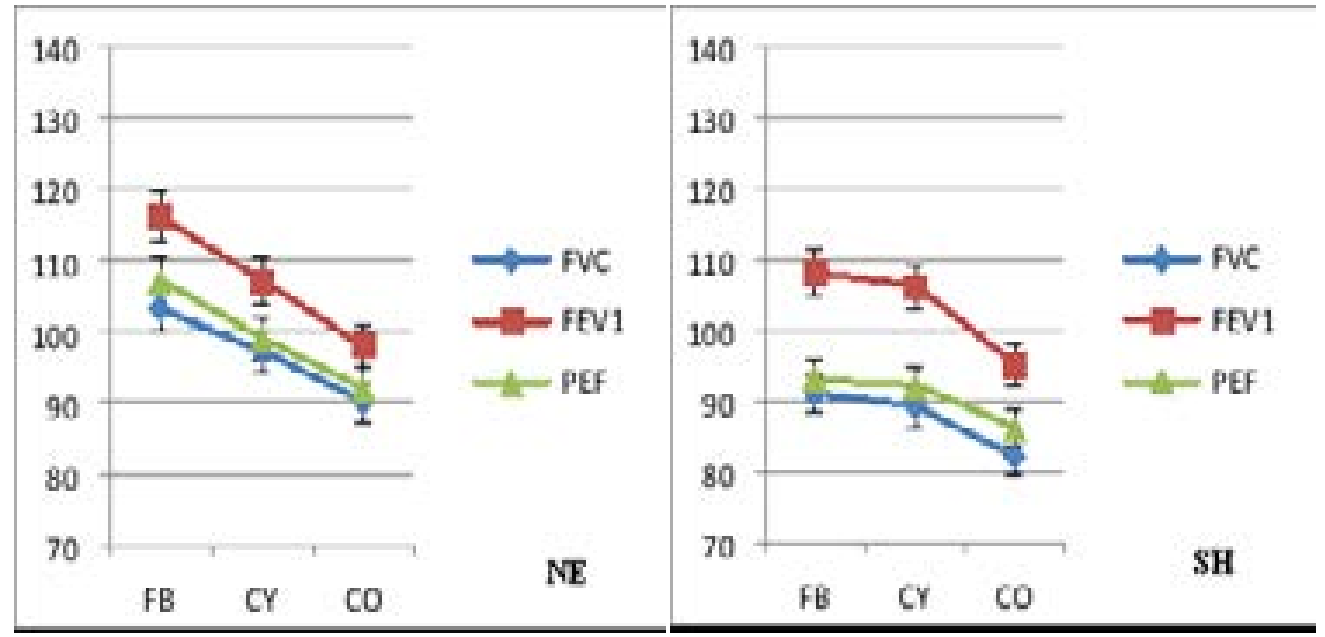

Figure 1 Comparative measures of the lung function parameters and significant MANOVA when compare among football players (FB), cyclists (CY), and control (CO) groups, distinctly in the non-exposed to tobacco smoking $(\mathrm{NE})$ and second-hand smoking $(\mathrm{SH})$.

The comparison between $\mathrm{SH}$ and $\mathrm{NE}$ inside the three groups of children, there was statistically non-significant changes between $\mathrm{SH}$ and $\mathrm{NE}$ subgroups in lung function parameters $(\mathrm{p}>0.05)$ as showed in Figure 2.

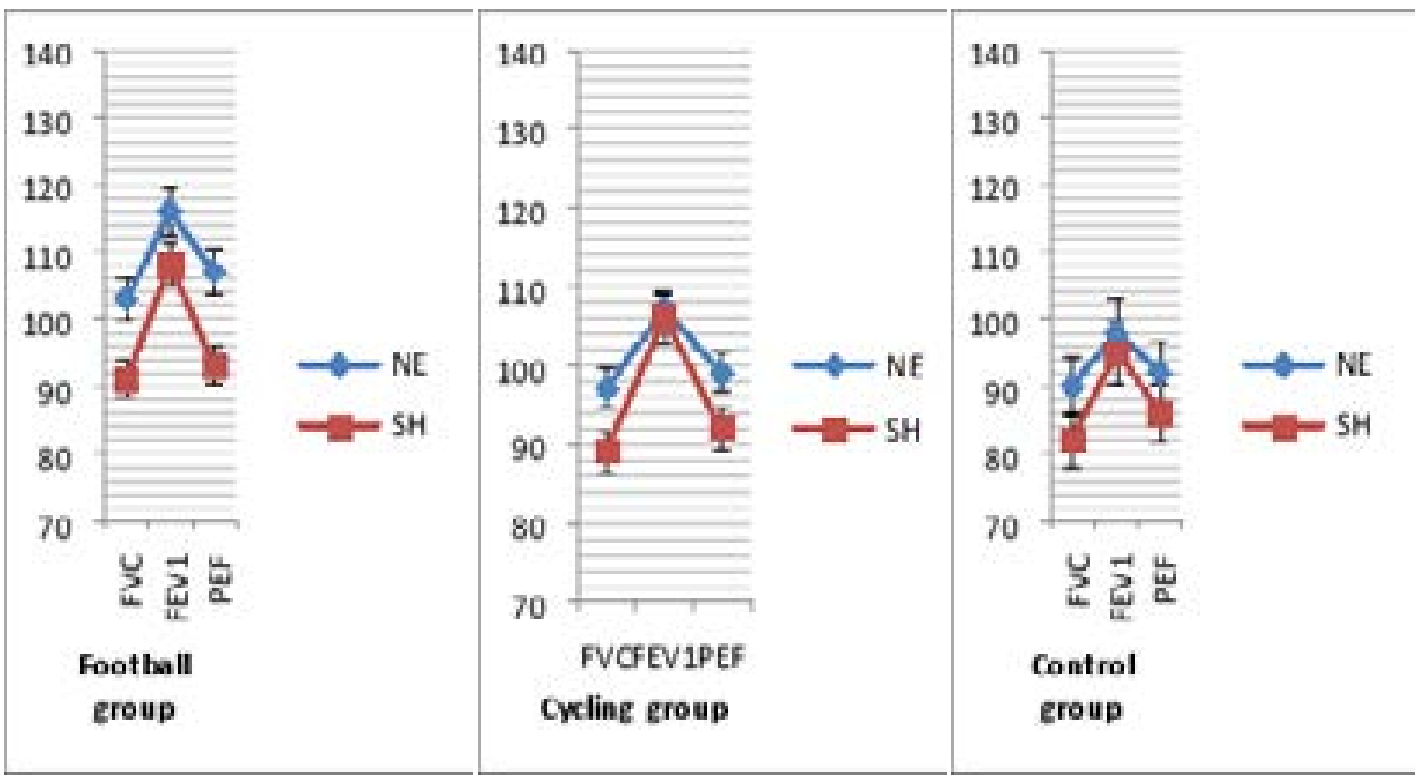

Figure 2 Comparative measures of the lung function parameters and significant MANOVA when compare between the NE and SH groups in the football players (FB), cyclists (CY), and control (CO) groups. 
The findings showed a higher consistent factor structure in the NE than in SH sub-groups. Additionally, the peak expiratory flow in the $\mathrm{SH}$ is protruded on the factor $\mathrm{A}$ of the FVC and FEV1. However, very evident and without doubt explainable factors are taken out in the NE children, the factor A of the FVC and FEV1 and the factor $\mathrm{B}$ of the peak expiratory flow as demonstrated in Table 2.

Table 2: The factor structure and the relationships' character among the lung function measures

\begin{tabular}{lcccc}
\hline \multirow{2}{*}{ Variables } & \multicolumn{2}{c}{ SH } & \multicolumn{2}{c}{ NE } \\
\cline { 2 - 5 } & Factor A & Factor B & Factor A & Factor B \\
\hline $\begin{array}{l}\text { Forced vital capacity } \\
\text { Forced expiratory volume in } 1\end{array}$ & 0.96 & 0.06 & 0.91 & 0.19 \\
sec & 0.88 & 0.35 & 0.79 & 0.45 \\
Peak expiratory flow & 0.69 & 0.41 & 0.29 & 0.68 \\
Variance explained & 3.19 & 1.99 & 2.59 & 2.41 \\
Total proportion & 0.51 & 0.31 & 0.43 & 0.39 \\
\hline
\end{tabular}

Abbreviations: SH, second-hand smoking; NE, non-exposed to tobacco smoke.

\section{Discussion}

The present study aimed to ascertain the effects of second-hand smoking on lung functions in athlete and non-athlete school-aged children hypothesizing that the dynamics differences of sports activities may lead to definite changes in maximum oxygen consumption for those football and cycling groups and suggested the feasible different influences in the lung functions of the two studied sportive activities. However, there was non-significant difference between the football, cycling and control groups in the baseline characteristics.

It was observed that there were differences in BMI which football and cycling groups were lower in values than control non-athlete group were expected but this difference was statistically non-significant. Previous studies approved that additional physical activity in school-aged children results in a higher systemic differences in the anthropometric measures than the less physical activity group. ${ }^{15-17}$ The findings of the current study clarified that there was non-significant difference in age, gender, body weight, height, and BMI among the three groups.

The beneficial effects of physical activity on lung functions are still limited. The results of previous study provided that lung functions were not increased by improving capability of lung inflation and deflation in young female swimmers. ${ }^{18}$ Nevertheless, Courteix et al approved that physical activity clearly enhances respiratory growing by reconciling the maturation of the respiratory system including air duct and alveoli space. ${ }^{12}$

The present study showed the significant increasing of the football and cycling in the variables of lung function more than the less physical activity group, the results showed a beneficial effects of sports activities on the lung functions in school-aged children. But, there were non-significant changes between the football and cycling in the assessed parameters.

Our study suggested two feasible concepts for this situation. One concept, sport activities (football and cycling) for two years have positive influences on the lung functions in school-aged children. It is particularly evident when find the slight increasing of lung functions in the football group than cycling group.

Therefore, it explains that the mechanical characteristics of the football sport and the greater oxygen uptake ensure a higher reproductive concept for the development of lung function, mainly by promoting large pulmonary expeditions. Another concept explained that dynamic characteristics may lead to improvement of lung volumes and ventilation with unnecessarily regarding prominent or sizable alveoli. ${ }^{19}$ The study groups showed significant measures of lung functions, without statistical difference 
between football and cycling groups. Assessment of the relative lung functions showed non-significant differences in lung function parameters between football and cycling groups. In addition, the comparative the lung function parameters were assessed using the linear correlation of the age and body height. ${ }^{20,21}$ Linear regression supposed an increasing of the lung function parameters with an increasing of the body height, as long as pulmonary functions, which actually adheres to the increasing of the body dimensions, is commonly defined as an increasing of the body height.

Recent study found a nonlinear correlation between body height and lung functions. ${ }^{22}$ The linear correlation of the comparative parameters of the lung function appropriately approximates individuals who have more height than peers (in the current study, there were non-significant differences in body height among the three groups). Many studies indirectly encouraged the nonlinear correlations of the body proportions in the individual execution. ${ }^{23-25}$ The significant differences in the FVC and FEV1 which were early analyzed comes in PEF, where the athlete groups scored higher lung volumes than the non-athlete group. But, the slight changes between the two sports activities early observed in the FVC and FEV1 values are statistically non-significant in PEF value. However, the previous discussed changes we discussed are considerable solely in the sub-group of children who were non-exposed to tobacco smoking. Accurately, comparison between the second-hand smokers in the three groups (football, cycling, and control), the present study showed non-significant differences in lung functions.

According to the outcomes of the current study and statistical analysis, second-hand smoking has non-significant effect on the lung functions in the school-aged children. Even so, it is very important to regard that the respiratory parameters of the second-hand smoking children are commonly lesser than non-exposed children in the three groups of the study (football, cycling, and control). The results of this study showed non-significant changes between the second-hand smokers and the non-exposed groups in FVC, FEV1 and PEF values. Supposing that, Many prior researches documented a bad effects of the second-hand smoking on the lung functions ${ }^{26}$, or reduction of lung functions with statistical non-significant differences ${ }^{27}$, while others found a dose-effect relationship. ${ }^{10}$ Because of reduction of the lung function pa- rameters in second-hand smoking, researchers expected the large significant differences between the second-hand smoking and non-exposed sub-groups after long time exposing to passive tobacco smoking. This expectations were confirmed by prior publications which reported a significant bad effects of second-hand smoking in old youngsters than the school-aged children of the current study. ${ }^{10,14}$ The current study observed non-significant changes between second-hand smoking and non-exposed subgroups in the two athlete groups. In agreement with this observation, recent study approved non-significant differences in lung function parameters relationships between the two sub-groups, second-hand smoking and non-exposed children. ${ }^{28}$

Concisely, the lung function parameters (FVC, FEV1, and PEF) were highly positive correlation in the non-exposed children in spite of, respiratory volumes are functionally assessed by measuring these parameters and affected by the same reason. On the other hand, there was a weak correlation among lung function parameters in the second-hand smokers and non-significant reduction of the lung function parameters, clarifying a weak coefficient correlation among the parameters which have be strongly correlated. ${ }^{28}$ This non-significant effects of second-hand smoking is still not clear, however these findings suggested some reasonable factors such as, physical activity levels, ingeniously excited and abridged breathing in passive smokers, dose-effect, and exposure duration to passive smoking. The exposure duration and dose-effect factors are hypothesized to impair lung functions, while the level of physical activity and abridged breathing decreases the negative effects of second-hand smoking on the lung functions.

In addition, the present study established the feasible changes in the correlations among lung function parameters in the second-hand smokers and non-exposed children using a factor analysis. When there was difference in the correlations in the two athlete groups, there could be a strongly corroborated to the previously explained.

Moreover, in the second-hand smokers, the peak expiratory flow is presented on the factor A of the forced vital capacity and forced expiratory volume in $1 \mathrm{sec}$. However, very evident and without doubt explainable factors are taken out in the non-exposed children, the factor A (the forced vital capacity and forced expiratory volume in $1 \mathrm{sec}$ ) and the factor B (the peak expiratory flow). As 
the analysis of factor structure is primary according to presented relationships among the study parameters, it confirm the outcomes of the prior study suggesting the non-significant bad impacts of the second-hand smoking on the lung functions are corroborated in this condition. ${ }^{29}$

It was provided that all parameters in the second-hand smoking were more dissipated than the parameters in the non-exposed children. As variation of the findings identifies significant differences between second-hand smoking and non-exposed children, it is an additional cause explained non-significant difference between the second-hand smoking and non-exposed subgroups in all the lung function parameters, in spite of slight mean changes which observed in many children.

\section{Conclusion}

Based on the outcomes of the current study, it was concluded that athlete children have more lung functions than age-related non-athlete peers, suggesting a feasible positive effects of sportive activities on the lung functions, confirming the study hypothesis. These results clarify that the dynamics specification of the football has similar effects to static specification of cycling on the lung functions opposing the second part of the hypothesis of the study. Hence, the results showed non-significant difference between second-hand smoking and non-exposed children in lung functions, certainly as the great variations of the findings which disallow to achieve the valuable significance level. Additionally, our study examined short age interval of school-aged children, while the significantly differentiated the lung functions values between second-hand smoking and non-exposed children was early frequently reported in aged children.

\section{Acknowledgement}

This publication was supported by the Deanship of Scientific Research at Prince Sattam bin Abdulaziz University. The authors gratefully acknowledge all parents and caregivers who supported their children to participate in this study.

\section{Funding}

No fund was received for this study.

\section{Conflicts of interest}

None declared.

\section{Ethical approval}

All the study procedures which carried out including human participants were based on the ethical standards of the institutional and/or national research committee and with the 1964 Helsinki Declaration and its later amendments or comparable ethical standards.

\section{References}

1. Fernández-Plata R, Rojas-Martínez R, MartínezBriseño D, García-Sancho C, Pérez-Padilla R. Effect of passive smoking on the growth of pulmonary function and respiratory symptoms in schoolchildren. Rev Invest Clin. 2016 May-Jun;68(3):119-27.

2. Report on the Global Tobacco Epidemic. World Health Organization. Cigarette Protect People Tobacco Smoke. (Accessed Nov 03, 2015).

3. Irvine L, Crombie IK, Clark RA, Slane PW, Goodman KE, Feyerabend C, et al. What determines levels of passive smoking in children with asthma? Thorax. 1997 Sep;52(9):766-9.

4. Cook DG, Strachan DP, Carey IM. Health effects of passive smoking. 9. Parental smoking and spirometric indices in children. Thorax. 1998 Oct;53(10):884-93.

5. Mallol J. Childhood asthma in developing countries. Low income aspects and related matters. Allergol Immunopathol (Madr). 2000 Sep-Oct;28(5):283-6.

6. Li YF, Gilliland FD, Berhane K, McConnell R, Gauderman WJ, Rappaport EB, et al. Effects of in utero and environmental tobacco smoke exposure on lung function in boys and girls with and without asthma. Am J Respir Crit Care Med. 2000 Dec;162(6):2097-104.

7. Peric M, Cavar M, Zenic N, Sekulic D, Sajber D. Predictors of competitive achievement among pubescent synchronized swimmers: an analysis of the solo-figure competition. J Sports Med Phys Fitness. 2014 Feb;54(1):1626.

8. Nuhoglu C, Gurul M, Nuhoglu Y, Karatoprak $\mathrm{N}$, Sonmez EO, Yavrucu S, et al. Effects of passive smoking on lung function in children. Pediatr Int. 2003 Aug;45(4):426-8.

9. Haby MM, Peat JK, Woolcock AJ. Effect of passive smoking, asthma, and respiratory infection on lung function in Australian children. Pediatr Pulmonol. 1994 Nov;18(5):323-9.

10. Rizzi M, Sergi M, Andreoli A, Pecis M, Bruschi C, Fanfulla F. Environmental tobacco smoke may induce early lung damage in healthy male adolescents. Chest. 2004 Apr;125(4):1387-93. 
11. Wang X, Wypij D, Gold DR, Speizer FE, Ware JH, Ferris BG Jr, et al. A longitudinal study of the effects of parental smoking on pulmonary function in children 6-18 years. Am J Respir Crit Care Med. 1994 Jun;149(6):1420-5. 12. Courteix D, Obert P, Lecoq AM, Guenon P, Koch G. Effect of intensive swimming training on lung volumes, airway resistance and on the maximal expiratory flow-volume relationship in prepubertal girls. Eur J Appl Physiol Occup Physiol. 1997;76(3):264-9.

13. Nourry C, Deruelle F, Guinhouya C, Baquet G, Fabre C, Bart F, et al. High-intensity intermittent running training improves pulmonary function and alters exercise breathing pattern in children. Eur J Appl Physiol. 2005 Jul;94(4):415-23.

14. Goić-Barisić I, Bradarić A, Erceg M, Barisić I, Foretić N, Pavlov N, et al. Influence of passive smoking on basic anthropometric characteristics and respiratory function in young athletes. Coll Antropol. 2006 Sep;30(3):615-9.

15. Dowda M, Ainsworth BE, Addy CL, Saunders R, Riner W. Environmental influences, physical activity, and weight status in 8- to 16-year-olds. Arch Pediatr Adolesc Med. 2001 Jun;155(6):711-7.

16. Mukhopadhyay A, Bhadra M, Bose K. Anthropometric assessment of nutritional status of adolescents of Kolkata, West Bengal. J Hum Ecol. 2005;18(3):213-6.

17. Sekulic D, Krstulovic S, Katic R, Ostojic L. Judo training is more effective for fitness development than recreational sports for 7-year old boys. Pediatr Exerc Sci. 2006;18(3):329-38.

18. Zinman R, Gaultier C. Maximal static pressures and lung volumes in young female swimmers: one year follow-up. Pediatr Pulmonol. 1987 May-Jun;3(3):145-8.

19. Merkus PJ, ten Have-Opbroek AA, Quanjer PH. Human lung growth: a review. Pediatr Pulmonol. 1996 Jun;21(6):383-97.
20. Malina RM, Bouchard C, Bar-Or O. Growth, maturation, and physical activity. $2^{\text {nd }}$ ed. Human Kinetics; 2004.

21. Knudson RJ, Slatin RC, Lebowitz MD, Burrows B. The maximal expiratory flow-volume curve. Normal standards, variability, and effects of age. Am Rev Respir Dis. 1976 May;113(5):587-600.

22. Boskabady MH, Tashakory A, Mazloom R, Ghamami G. Prediction equations for pulmonary function values in healthy young Iranians aged 8-18 years. Respirology. 2004 Nov;9(4):535-42.

23. Hoff J, Kemi OJ, Helgerud J. Strength and endurance differences between elite and junior elite ice hockey players. The importance of allometric scaling. Int J Sports Med. 2005 Sep;26(7):537-41.

24. Markovic G, Jaric S. Movement performance and body size: the relationship for different groups of tests. Eur J Appl Physiol. 2004 Jun;92(1-2):139-49.

25. Sekulić D, Zenić N, Marković G. Non linear relationships between anthropometric and motor-endurance variables. Coll Antropol. 2005 Dec;29(2):723-30.

26. Cook DG, Strachan DP, Carey IM. Health effects of passive smoking. 9. Parental smoking and spirometric indices in children. Thorax. 1998 Oct;53(10):884-93.

27. Bek K, Tomaç N, Delibas A, Tuna F, Teziç HT, Sungur M. The effect of passive smoking on pulmonary function during childhood. Postgrad Med J. 1999 Jun;75(884):339-41.

28. Sekulic D, Tocilj J. Pulmonary function in military divers: smoking habits and physical fitness training influence. Mil Med. 2006 Nov;171(11):1071-5.

29. Sekulić D, Viskić-Stalec N, Rausavljević N. Non-linear relations between selected anthropological predictors and psycho-physiological exercise-responses. Coll Antropol. 2003 Dec;27(2):587-98. 